\title{
Timing and intensity of exercise for glucose control. Reply to Chacko E. [letter]
}

\author{
Frank W. Booth • John P. Thyfault
}

Received: 25 July 2014 / Accepted: 31 July 2014 / Published online: 23 August 2014

(C) Springer-Verlag Berlin Heidelberg 2014

Keywords Aerobic fitness · Exercise prescription ·

Glycaemic control $\cdot$ Lean body mass

To the Editor: Dr Chacko [1] is to be congratulated for her consideration of the timing and intensity of physical activity upon improvements in glycaemic control in type 2 diabetic patients. She suggests that the best timing for moderate exercise to improve glycaemic control in patients with type 2 diabetes is between the 30 and 90 min post-meal mark. While her and the field's focus on improving glycaemia with exercise is a valuable starting place, this exercise prescription is unlikely to produce the optimal health benefits for longevity that exercise can provide in this growing population. To optimally improve health, increasing and maintaining fitness and lean body mass must be considered. As regards fitness, a $60 \mathrm{~min} /$ day walking only prescription would not meet the weekly metabolic equivalents (METS) threshold that has been shown to result in a 10 year reduction in coronary heart disease risk in high-risk patients [2]. Furthermore, walking exercise alone may not maximally increase, or maintain, cardiovascular fitness and lean muscle mass, the latter of which must be maintained in order to continue walking and physical activity throughout the ageing process. Our point here is simple: although our first goal should be to increase physical activity, we must also provide type 2 diabetic patients with the crucial ammunition needed for battling further disease development and living a healthy, long life [3]. Thus, using exercise to improve glycaemic control in addition to maintaining aerobic fitness and lean body mass (strength) should all be a part of the 'exercise formula' prescribed to patients with, or at risk of developing, type 2 diabetes.

Funding This work was partially supported by NIH grant DK088940 (JPT).

Duality of interest The authors declare that there is no duality of interest associated with this manuscript.

Contribution statement Both authors were responsible for the conception and design of the manuscript, drafting the article and revising it critically for important intellectual content. Both authors approved the version to be published.

\section{References}

1. Chacko E (2014) Timing and intensity of exercise for glucose control. Diabetologia. doi:10.1007/s00125-014-3339-0

2. Balducci S, Sacchetti M, Haxhi J et al (2014) Physical exercise as therapy for type 2 diabetes mellitus. Diabetes Metab Res Rev 30(Suppl 1):13-23

3. Winett RA, Davy BM, Marinik E et al (2014) Developing a new treatment paradigm for disease prevention and healthy aging. Transl Behav Med 4:117-123
F. W. Booth $(\bowtie) \cdot$ J. P. Thyfault

Health Activity Center, University of Missouri, 1600 East Rollins St, Colombia, MO 65211, USA

e-mail: boothf@missouri.edu 